\title{
Corporate Social Responsibility Disclosure and Employee Commitment: Evidence from Libya
}

\author{
Nagib Salem Bayoud \\ School of Accounting, Economics and Finance, Faculty of Business and Law \\ University of Southern Queensland (USQ), Australia \\ E-mail: NagibSalemBayoud@y7mail.com \& Nagib.Bayoud@usq.edu.au
}

Marie Kavanagh

School of Accounting, Economics and Finance, Faculty of Business and Law

University of Southern Queensland (USQ), Australia

E-mail: marie.kavanagh@usq.edu.au

Geoff Slaughter

School of Accounting, Economics and Finance, Faculty of Business and Law

University of Southern Queensland (USQ), Australia

E-mail: geoff.slaughter@usq.edu.au

Received: January 27, 2012

Accepted: March 5, $2012 \quad$ Published: May 1, 2012

doi:10.5539/ijef.v4n5p37

URL: http://dx.doi.org/10.5539/ijef.v4n5p37

\begin{abstract}
Most research on corporate social responsibility disclosure (CSRD) describes its relationships with external factors such as financial performance and corporate reputation. There are relatively few studies that have focused employee's behaviours towards CSRD. This paper examines the relationship between CSRD on employee commitment. An exploratory approach is used in this paper by this study. This study utilizes interview method to collect data from 31 financial managers and information managers of 22 organisations; Miles and Huberman (1994) approach is used to analyse the qualitative data. The researchers have chosen the Libyan context as one of the world's developing countries that has undergone many changes over a short period of time in terms of economic, environmental and social changes. The majority view of managers interviewed is that as CSRD related to employee activities and consumer activities increases employee commitment towards its company increase. However, there is no relationship between CSRD related to environmental and employee disclosures and employee commitment in Libyan companies. The study discusses and explains important implications regarding uses of CSRD for enhancing employee's commitment.
\end{abstract}

Keywords: Corporate social responsibility (CSR), Corporate social responsibility disclosure (CSRD), Environmental disclosure (ENVD), Consumer disclosure (COND), Community involvement disclosure (COMD), Employee disclosure (EMPD), Employee commitment (EC) and stakeholder theory

\section{Introduction}

Major corporate ethical disasters impacting on the environment, human resources, and the community have heightened the demand for public firms to voluntarily disclose their CSR activities to stakeholders. As a result, CSR and disclosure have become an important issue in the business world (Waller \& Lanis 2009). In addition, CSRD is an extension of the financial disclosure system, which reflects the wider anticipation of society concerning the role of the business community in the economy. Furthermore, with the rapid collapse of cross-border economic barriers and the globalization of business, the role of CSR is being debated in an international arena (van der Laan Smith et al. 2005). The World Business Council for Sustainable Development (WBCSD) (1998, p. 3) defined CSR as: 'the continuing commitment by business to behave ethically and contribute to economic development while improving the quality of life of the workforce and their families as well as of the local community and society at large'. Also Mathews (1993) has defined CSRD as: organisations voluntarily disclosing both quantitatively and qualitatively 
about their CSR activities in order to inform their stakeholders. According to these definitions, CSR activities and disclosures play relevant roles in organisational performance. In addition, CSRD includes many activities such as community, environmental, employee, investor, customer, and supplier responsibilities.

There is growing attention towards the impact of CSR and disclosure, in particular about environmental activities on company performance for many years. There has been only a limited emphasis on CSR and disclosure related to employees and the possible impacts of CSRD on performance in terms of employee commitment. Therefore, this paper attempts to explore the relationship between CSRD and employee commitment in order to cover this neglected aspect of CSRD research.

The number of studies investigates increases to identify the relationship between CSR and CSRD with employees commitment has increased in recent years (Branco and Rodrigues, 2006). Regarding employees, the benefits of CSR and CSRD in terms of the impact on employees has been related to know-how, corporate culture and corporate reputation (Branco \& Rodrigues 2006). Consequently, CSRD is perceived to be of a significant importance in enhancing corporate reputation through improving employee commitment (Branco \& Rodrigues 2008; Hasseldine et al. 2005; Toms 2002).

Although most companies disclose CSR activities to obtain the external factors such as improved reputation and financial performance, there are other reasons that are internal factors related to their employees. This paper contends the importance of using CSRD to improve the employee commitment of a company. The argument outlined in the literature review illustrates the importance of CSRD to employees and their companies. Most companies perceived to have a high level of CSR activities have an increased ability to attract and to retain employees, and to maintain employee morale. This, in turn, leads to reduced recruitment, training costs, and turnover (Albinger and Freeman, 2000; Backhaus et al., 2002; Greening and Turban, 2000; Peterson, 2004; Turban and Greening, 1997). Therefore, CSRD may enable a company to maintain a positive image with its employees and lead to improved company reputation. This factor also leads to developing capabilities and employee-related internal resources and organizational efficiency.

To date, research on the relationship between CSRD and employee commitment has been limited to the use of either quantitative or qualitative data. The paper provides interviews with thirty one financial managers and information managers. The paper has one objective which is to explore and understand the relationship between CSRD and employee commitment.

The paper is organized as follows. Section 2 outlines the literature review and research framework. Section 3 outlines the research methods in terms of the sample and the data collection, the interview process and analysis of information. Section 4 outlines the results of this study. Finally, sections 5 and 6 discuss the results and show summary and conclusion.

\section{Literature Review and Research Framework}

Employees consider one of the most important factors in a firm; they affect an organisation. Therefore, "the effective delivery of corporate social and environmental responsibility initiatives is dependent on employee responsiveness" (Collier et al. 2007, p. 22). In recent years, employee commitment is one of the most studied indicators of the strategies value of CSR. According to Jaworski and Kohli (1993, p 60) defined (as cited in (Rettab et al. 2009)) employee commitment

"[T]he extent to which a business unit's employees are fond of the organisation, and see their future tried to that of the organisation, and are willing to make personal sacrifices for the business unit"

Carroll (1979) notices that CSR and community contributions and reflects the way in which the firm interacts with the physical environment and its ethical stance towards consumers and other external stakeholders. External CSR on internal and external information sources including the media and their personal experience within the company may be expected to base their employee opinions about these activities. Employees and managers have a greater stake in the success of the corporation than investor, owners, because their jobs and economic livelihood are at stake (Post 2003). Branco and Rodrigues (2006) discussed that CSRD leads to important results on the creation or deletion of other fundamental intangible resources, and may help build a positive image with employees and managers. Some studies expected that there is a positive relationship between CSR and employee commitment (Backhaus et al. 2002b; Brammer et al. 2007; Maignan \& Ferrell 2001, 2004; Peterson 2004). Furthermore, Albinger and Freeman (2000), Backhaus, Stone and Heiner (2002b), Greening and Turban (2000), Maignan, Ferrell and Hult (1999), and Peterson (2004) revealed that there is relationship between CSR and employee commitment. At the same time, relationship between procedural justice and affective commitment may be expected a positive because employees may be expected to identify with ethical organizations(Brammer \& Millington 2005). The existing literature 
provides compelling empirical support for these arguments; a strong relationship has been found between the ethical climate of organizations and job satisfaction(Koh \& Boo 2001; Viswesvaran et al. 1998) and studies of the relationship between organizational commitment and procedural justice suggest that they are positively and significantly related (Albinger \& Freeman 2000; Backhaus et al. 2002a; Cohen-Charash \& Spector 2001; Greening \& Turban 2000; Meyer et al. 2002; Peterson 2004; Turban \& Greening 1997) illustrated that a firms social responsibility deals with matter to its employee and expect to have a positive impact on employees commitment. In addition, Maignan et al (1999) expected that firms that disclose in CSR activities might enjoy enhanced levels of employee commitment for two reasons: they have devoted to ensuring the quality of workplace experience, and they inform their stakeholders about social issues such as the welfare of the community or the protection of the environment.

Rupp et al (2006) noticed that employees' perceptions of their firms CSR activities lead their perceptions of the firm. In addition, firms that disclose CSR activities work to ensure their employees protect through fair and socially responsible practices (Rupp et al. 2006). Thus, it can be seen that firms that engage in CSR activities and disclosure will appear a positive relationship with their employee commitment because they might earn employees commitment compared with firms that do not engage in CSR activities (Aguilera et al. 2007). Exploring a positive relationship between CSR and financial performance is more likely to lead a positive relationship between CSR and employee commitment. Rettab, Brik \& Mellahi (2009) explored that there is a positive relationship between CSR and employee commitment in the UAE market. One the other hand, Turker (2009) found that there is no link between CSR to government and the commitment level of employee by using social identity theory.

Most of the studies above indicated that there is a positive relationship between CSR and disclosure with employee commitment, whereas few studies found a negative, no significant and fixed relationship between them. In addition to that there is limited research that has investigated CSRD and employee commitment either in developing countries especially in Libya. In addition, no known study has examined the relationship between CSRD and financial performance in Libya. Therefore, we asked our interviewees for their views on the relationship between higher levels of CSRD provided by firms and its higher employee commitment in Libya. This was to obtain a sense of how higher levels of CSRD provided by firms are positively associated with higher employee commitment among firms in Libya.

\section{Research Methods}

\subsection{Sample and Data Collection}

This paper was to gather information from face to face of semi-structured interview. Interviews with one of the most important social and environmental stakeholder groups were conducted to help the researchers to gather data relevant to this issue. In addition, knowledge gathered from consulting with other researchers in CSRD and literature reviews enabled the researchers to design an interview guide with common questions in order to ask the interviewees (see appendix 1). The questions were focused on the disclosure of information that is considered for the study is merely through published annual reports and its relationship with employee commitment in Libya.

Appendix 1 shows that financial managers and information managers were interviewed because they have to some extent formulated opinions on CSRD while preparing annual reports. The total number of interviewees was 31 from 22 organisations of different sectors. Twenty-four (77\%) interviewees were financial managers and seven (23\%) were information managers. According to the level of CSRD in the selected sectors, twenty two companies in the four sectors were selected as having the higher level of CSRD.

\subsection{Interview Process and Analysis of Information}

This paper consists of the above mentioned 40 firms which were collected in the quantitative stage. Thirty one managers were interviewed to express their perceptions about the relationship between CSRD and employee commitment. Data gathered from interviews was recorded by a note and tape recorders with financial managers and information managers of the firms enabled the researchers to gain the deeper insights on this issue in this research. The interviews took place between October 2010 and February 2011. Interviews lasted between twenty minutes to one hour and half. The meetings were held in the manager's office.

Miles and Huberman (1994) approach was used to analyse the qualitative data. CSR activities were classified into four categories (employee, community involvement, consumers and products and environment). Analysing the qualitative data was employed in two stages. First, the researchers classified the interview content (transcript) into similar or different responses. Second, identifying key, substantive points and putting them into categories were the two main aspects involved in the current study (Gillham 2000). Identifying a code was the first analysis process with each transcript. Then all the transcripts were readable more than one time by the researcher. At the same time, they 
highlighted the substantive statements that were related to the research focus (Gillham 2000; Marshall \& Rossman 1999). After going through all the transcripts, at the same time which the researchers went back to read the first one of the transcripts, they listened to the tape in order to find any intonations and statements that they have failed to highlight (Kamla 2007). A very big representation of statement from interviews was resulted by this stage, which involved further composition. After that, the researchers gave the highlighted and statements simple heading through derivation a set of categories for the responses to each question (Gillham 2000). These categories and headings checked against the highlighted statements and any necessary amendments were made. The researchers repeated this procedure more than one time to ensure that no categories and headings were missed (Hanafi 2006). Subsequently, each broad research question employed a big sheet in the form of a matrix. The matrix sheets entered these questions which classified categories and headings into them. The researchers then went through the transcripts, assigning each highlighted statements to a category (Gillham 2000). In addition, the researchers maintained a second separate file to record the overall observations in the meaning of data for all interviews.

The same mentioned procedures have been applied in the four CSR categories. The researchers used two stages. First stage was to identify the type of interview content response if similar or different. The second stage was to identifying the items of CSR categories in to the four categories (employee categories, environmental categories, consumer categories and community involvement categories) through identifying a code with each transcript. Then all the transcripts were reviewed with the tape in order to find any intonations and statements that they have failed to highlight related to each category (CSR categories). The previous procedure was used more than one time to ensure that headings related to CSR categories were missed. After that, the researchers used the matrix sheets which include all questions and headings regarding each CSR categories. According to the previous stages, therefore the researcher could collect all data and information related to each CSR categories to identify the relationship between higher levels of CSRD and employee commitment in Libya.

\section{Results}

After accurate reading and reflecting on the transcripts, ordinal categories were developed by the researcher for the responses related to the key topics and questions that were asked. The researcher summarise the following findings in appendix 2. Appendix 2 was used for ease of interpretation; one answer represents the view of each interviewee on a specified topic. Hence the answers in appendix show the perception of financial managers and information managers in Libyan companies about the association between CSRD and employee commitment.

\subsection{The Perceptions of Libyan Managers on the Relationship between CSRD and Employee Commitment}

\subsubsection{The Association between CSRD and Employee Commitment}

The current study investigates the association between CSRD and employee commitment with considering the responsibilities and the interests to different stakeholders. Some prior studies have identified how CSR and CSRD are related to employees in terms of the commitment (Branco \& Rodrigues 2009; Hsu 2006; Kleiner \& Morris 1988; Peccei et al. 2005). These studies supported the notion that CSR and CSRD can increase its attractiveness as an employer.

The researcher asked whether greater levels of CSRD would be associated with employee commitment through the three questions (see appendix 2). The answers were identical with the majority of interviewees about the relationship between each category of CSRD and employee commitment.

The researcher asked the first question about whether levels of each category of CSRD have a potential effect on employee commitment of a company. There were different opinions about the effect of each category on employees. To obtain deeper understanding about the potential effect of both employee disclosure and consumer disclosure on employee commitment, the majority of interviewees were in agreement about the existence of this effect. Twenty one managers $(68 \%)$ confirmed that employee activities and level of employee disclosure have the biggest impact employees via increasing their commitment towards their companies and three $(10 \%)$ said that a certain level of employee disclosure would have affect employee commitment with credibility, transparency and employee activities as mentioned by some interviewees:

When employees are convinced of this information compared with what the bank really performed, this information about social activities will give them the satisfaction which lead to fulfil their duties in the bank... also, although some services did not present to all employees, such as treatment of difficult cases, which require large amounts of money to a small group of employees, we noted that the publication of this information ensured increasing employees understanding about what the extent of the company interest, which gave them the incentive to perform their jobs. 
In addition, disclosure about the interest of a company towards their employees such as employees training, employees rewards, employees safety, salary value and so on could push some persons who have high skills and long experience to prefer a job in this company as well as increasing its attractiveness as an employer. Furthermore, employee disclosure gives most employees good motivation to use all their abilities for achieving company goals.

Informing employees about activities of the bank, especially employee activities, such as employee training, employee health and employee remuneration have given an incentive and motivation to employees for committing and improving their performance in order to get these features... Also disclosure of these activities attracted some skills and experiences to work in the company...for example, when the company has prepared the annual report 2009, which showed the information about employee remuneration, this information motivated the employees to say, we could work all day and at any time determined by the company for achieving the company goals.

while Twelve (39\%) believe that providing more consumers disclosure would definitely affect employee commitment, because this information would give employees the confidence and obtain their sense of belonging and pride towards the products that were offered by the company, this in turn were reflected on the employee's commitment.

Employees in this company had a feeling of satisfaction and belonging for their company as a result providing this products with a high degree of quality and great benefit to the consumer,... this led to increasing their attentions on the interests of the company and their performance, improving their discipline in work and motivate the performance of the employees... that reflected in their level of commitment for the continuation of the company in producing, developing and maintaining the quality of this product.

Furthermore, seven (23\%) said that an identified level of consumers disclosure could influence employee commitment, but with the considering of some factors. The credibility of disclosure about quality product and product development would be the biggest effect with a certain level of consumer disclosure compared with product safety. Moreover, positive information about consumer activities with a certain level of this information would have an effective impact on employee commitment as well as reputation.

For example, the company has replaced some idle machines with new ones and disclosing this active in its annual report, this gave a good image and increased employee's satisfaction, because of the important role that performed their company, its interest to satisfy customers, providing a good product and the maintaining on its good reputation.

Most interviewees see that both employee and consumers disclosure are more importance and useful than other categories, because most stakeholders in particular shareholders and employees noticed a lack of benefit from environmental and community disclosure compared with both information about employee and consumers activities to affect employee commitment.

It is noticeable in the company, most shareholders supported expense and disclosure of employees and consumers activities, while some shareholders (employees) are reluctant or hesitant in spending some money on both community and environment activities, because they consider it squandering of their money.

However, seven managers $(10 \%$ and $13 \%)$ believe that this effect on employee comment would not exist in a company, because employees did not realize the importance of employee disclosure and they focus only on the amount of their salaries and continuing their salaries due to their difference in level of culture and education.

We think that some employees are primarily interested in the continuation of obtaining on their salary, regardless of other things and this is due to the different level of the culture and education between the employees.

While eight of thirty one (26\%) believe that the application of labour laws, the effect of religion, level of culture, level of education and interests of stakeholders only could be more effective to commit employees for achieving their works to the fullest towards their companies, and some of them found some difficulties to measure employee commitment due to multiplicity and overlap of the above mentioned causes, therefore customer disclosure would not be likely to only affect employee commitment. In theory, the companies can notice the effect of consumer disclosure on employee commitment. Four (13\%) asserted that this effect practically does not be clear. All of these interviewees believe that both of employee and consumer activities could affect employee commitment, but not level of disclosure of them.

The difficulties to measure employee commitment and Multiplicity of its causes have been more difficult to determine the impact of the level of social disclosure, therefore the company did not measure this effect in the past, but I think that all of the Libyan environment determines such as religion, level of culture, level of education, laws, and interests of stakeholders have a greater role to affect the commitment of the employee...more specifically, it is noted in these companies that employees that do not have sufficient knowledge and do not have high education 
about employee activities and consumes activities did not care with the situation of their company, do not have good feeling towards their company, therefore this is reflected negatively on their performance within the company such as leaving work.

There was a wide vary of opinion expressed when the researcher asked whether greater level of community disclosure and environmental disclosure would affect employee commitment, but the majority of interviewees do not see the effect of community disclosure and environmental disclosure on employee commitment. Twenty managers $(13 \%$ and $52 \%)$ said that employee commitment would not be affected by level of community disclosure in the companies, because of a lack of the awareness of employees towards the importance of this disclosure and focus on what a company introduced to them, while fifteen (48\%) think a lack of the probability of environmental disclosure to affect on employee commitment, because companies do not inform their employees about this information disclosed. This result also was proved by (Ahmad 2005); he presented quantitative evidence from Libya as most Libyan companies did not tell their employees about environmental information disclosed through all the channels. They confirmed that the Libyan law sanction play a main role to improve employee commitments in the Libyan companies more than other reasons.

In fact, we do not care greatly over the impact of the dissemination of information about community and environmental activities in the preparation of the annual report on the commitment of the employees, because we believe the law of sanctions and rewards may be more impact on them.

In this context, three of financial managers $(10 \%)$ mentioned that this effect between environmental information disclosed and employee commitment exists and can affect financial performance and reputation of a company, but in theory.

Theoretically, the management of this company does not realize the importance of activities related to the community service contributions, especially donations probably do not enable the bank to obtain the benefits of disclosure regarding this activity and thus it affects negatively employee in addition to its impact on the financial performance of the bank and the reputation of the bank.

In the other hand, the findings found that five of financial managers $(16 \%)$ see that there would be an effect on employee commitment by level of community disclosure, while six (19\%) said that community disclosure and some mentioned factors could be an impact on employee commitment. In the other hand, four of financial managers (13\%) note that providing a great-practice level of environmental disclosure or better would allow employees to know about what the extent of the importance of environmental activities for a company, in particular inside a company, this in turn would be reflected on level of their commitment toward a company, while the remaining nine (29\%) believe that a certain level of environmental disclosure would not be adequate to affect employee commitment, because it considers the minor factor.

Yes, there is an impact on the commitment of the employee because the Islamic culture has a great role in the culture of the environment surrounding the company, so there is the impact of positive and up to that the employee can accept to continue working in the company that made and continue to contribute to society despite the lack of salary compared to other companies and that he was proud because of the work at this company.

Employees' recognition about the negative effects of company on the environment and its employees, particular who work in the management of production could create negative impact on their health and their level of satisfaction on their performance in the company and... some employees may leave their jobs to keep their health safety.

I think that the company does not take into account the protection of the environment through greenhouse gas emissions that have a negative effect and its disclosure would lead to reduced employee commitment and the inability of the employee to continue within the company and vice versa.

Related to the second question about identifying the association between employee disclosure and consumer disclosure with employee commitment, the findings found that twenty six (84\%) and twenty one of the interviewees $(68 \%)$ indicted a positive link between high level of both employee and consumer information disclosed and employee commitment. All of them said that disclosing of both employee and consumer disclosure in annual reports would give a type of loyalty to a company and would obtain sticking with this company.

We think that emerging information about the extent of interest companies related to quality and development of our products as well as employees training, employee safety and health and employee rewards through all canals Stimulates and increases belonging and striking employees towards their company.

However, only five managers (16\%) think no link between employee and employee commitment due to a lack of the interest of most employees in a company for reading this disclosure, while ten $(32 \%)$ see that there is no association between consumer disclosure and employee commitment for the same reason. They asserted that these employees 
were affected by the activities which performed their companies but not by what a company said in its annual reports.

We do not think that there is a relationship between both employee and consumers information with employee commitment... because most employees do not care with this information... but increasing both employee and consumer activities reflects positively with the commitment of employee.

One the other hand, the majority of interviewees believe that there is no link between both community and environmental information disclosed with employee commitment. Nineteen of thirty one managers $(61 \%)$ think that employees in the Libyan companies are not interested in information disclosed about both community and environmental activities which are prepared in their annual reports, but more their focus are on the activities that give some direct benefits such as employee activities. However, there were two opinions about the type of the association between community disclosure and employee commitment, one of interviewee (3\%) said that there is a negative association between them, but eleven managers (35\%) mentioned to exist a positive association.

Disclosure about the company contributions in the community service would be a negative effect on employee's performance, when the company spent its money on outside the company without the employee's interest, because the employees get few salaries.

Regarding the link between environmental disclosure and employee commitment, there is a general agreement between twelve of interviewees (39\%) that indicated a positive link.

Sure I think there is a positive relationship, because, in the one of previous years a company disseminated both financial and social information and some employees interacted with this information to be more effectiveness and importance. This led to developing this report and increasing the amount of information as the annual report in the past was not exceed five pages and now is not less than fifty pages. In addition, this information stimulated the employees who work in departments, particular that are issued this information in the report (such as financial section), as well, the company provided the letters of thanks and rewards for the preparation of this report. Moreover, there was clearly evident during the preparation of the report that all employees in the departments presented full cooperation so that each department sent its information to a competent administration in preparing the report quickly in order not to delay publication of this information.

Two of twelve interviewees said that the sort of the relationship between CSRD regardless the type of category used and employee commitment depended on the extent of the relationship between financial performance and CSRD, if positive the relationship was positive and vice versa. They think that a level of financial performance of a company would play an important role to identify attitude of employees, because high level of financial performance of a company would increase striking employees with their companies and would claim employees for improving their ability via maintaining a company performance.

Some employees are focused on the relationship between social disclosure and financial performance, and they think that this relationship has a positive interaction with employee commitment, when employee find social disclosure impact on the profitability and revenues and sales of the company, this creates a friendly kind of confidence and safety, and this in turn reflects on the loyalty towards their company because the company is financially stable and the relationships is interlocking between the company's interest and the interest of the employee.

The researcher also asked whether information disclosed about CSR activities can improve employee commitment. Approximately the same findings were expressed by most interviewees; two categories were used to improve the commitment of employees.

In respect of both of employee commitment and consumers disclosure with employee commitment, most interviewees confirmed that both of them could increase employee commitment. Eleven of thirty one (35\%) stated that great level of employee disclosure would help an increase of loyalty to this company and sticking with this organization, this increase would lead to the improvement of employee commitment, because employees in these companies are interested in the activities which are offered. In this regard, most employees seek to obtain these benefits such as remunerations, training, loans without any interests, etc. All of these benefits stimulate most employees to perform their duties to fullest towards their company, consequently, improving employee commitment. Six managers (19\%) believe that most employees feel proud when read some information concerning about their product and good services provided to consumer of their company through the annual report or other channels, such as the quality of a product or the development of a product or good facilities offered by their company to customers. Ten (32\%) asserted that positive information about employee activities would create good 
image/reputation which in turn was reflected on employees through performing their responsibilities towards their company and eleven managers (35\%) also confirmed the prior reason regarding consumer disclosure.

Yes, one of the reasons for the process of disclosure is to targets employees in order to gains their satisfaction and to gives a full picture of social activities provided by the company, thus this improves their commitment to the company... also providing positive information and detailed information about staff and quality products activities as well as products safety would reflect positively in increasing sales and this means that there is no goods stacked in warehouses which ensures continuing to benefit from the company in the form of salaries and other features, such as training and so on. All of these would stimulate and increase association between a company and its employees... also they would support an image and reputation of a company.

However, nine of the interviewees (29\%) said that employee disclosure could not improve employee commitment and thirteen (42\%) mentioned that there is no any improving in employee commitment due to providing good-practice of consumer disclosure. They commented that the reason may refer to a lack of informing of employees about this information and a lack of interest of both employee and consumers disclosure from some employees. The remaining one (3\%) did not know whether high level of both employee and consumers disclosure can lead improve employee commitment.

The main objective is to increase the share price, but the improvement of employee commitment comes implicit by the dissemination of this information and the effect of employee and consumer information is not obvious due to a lack of informing of employees and a lack of employee interest.

Most interviewees were general agreement that the Libyan companies did not use information disclosed about community and environmental activities for improving employee commitment. Twenty (65\%) and eighteen (58\%) managers believe that employees in their companies do not care with disclosure about both community and environmental activities and there is little information disclosed about both of these activities published in their annual reports, therefore increasing a level of information disclosed in both of these activities do not improve employee commitment in the Libyan companies. In addition to that, three of the interviewees $(10 \%)$ did not know whether this disclosure improve the commitment of employee.

Yes, a company presented some services to the community, for example, a company has opened branches in many urban and rural areas for the purpose of profitability and create jobs, this reflected positively on the employees in a company through improved performance. But I do not think that the amount of disclosure of this information increase or increased commitment to the employee in a company... and employees did not care with environmental information in particular if these activities did not affect their health, but focus on providing this activity.

On the other hand, few interviewees confirmed that high level of both community and environmental disclosure could improve employee commitment in their companies. Only one information manager (3\%) believe that a certain level of both community and environmental disclosure regardless the type of this information disclosed may improve employee commitment, while seven $(23 \%)$ see that the type of disclosure plays an important role to improve employee commitment and nine (29\%) also noticed the same thing. They believe that positive information about both community and environmental information disclosed may interact with employees' behaviours; this would lead to improve their commitment.

\subsubsection{More Details on Association CSRD with Employee Commitment}

The researcher also asked whether choice of accounting policy interact with the amount of CSRD policy to affect employee commitment. There were some variations about this question; most interviews see that accounting policy used (accounting principles) in their companies is not sufficient to interact with a level of CSRD for improving employee commitment. Eight managers of twenty eight $(29 \%)$ believe that accounting policy used in their companies would not interrelate with this information to affect the commitment of employee, with five (18\%) were not aware whether accounting policy used in their companies plays an important role with a level of CSRD to influence employee commitment. They think that obligation the Libyan companies to apply international accounting standards and privatization public companies as well as realizing the importance of CSR activities and its disclosure may create an effect on employee commitment through its interaction with the amount of CSRD.

Not enough but intention is to attempt to apply international accounting standards... privatization public companies... and realizing the importance of social activities... that provide and enable the Libyan companies that disclose more the amount of social information.

However, few numbers of interviewees see accounting policy used in their companies is adequate to interact with this relationship. Four (14\%) interviewees believe that accounting policy used cover most of employee and consumer activities items in terms of quantity disclosure. For example, all companies show employment cost in 
which includes employee salaries, employee health, employee training, employee remuneration, quality expenses, research and development expenses, etc. all of items were showed in statement income. In addition, annual reports showed some qualitative details about employee and consumer activities such as employee benefits, number of employees, service type and so on. While they noticed that accounting policy used in their companies were not enough to interact with some categories of another CSR activities to affect employee commitment. Eleven (39\%) said that there is possibility to interact this policy with some categories such as employee and consumer activities to influence employee commitment.

We show employee information and consumers information through applying accounting principles in the statement income such training costs, salaries costs, loans cost and quality costs of product, etc... This indicates that this policy works with these principles that are in turn reflected on the link between this information and employee commitment.

The research asked whether the effect of CSRD on employee commitment relay on establishing a sustained commitment to improve CSRD. Eight of the twenty eight interviewees (29\%) see that company's commitment to disclosing CSR activities in its annual reports would allow this information to affect employee commitment. They believe that this commitment came to obtain a company the benefits of disclosing CSR activities. One of the financial managers stated that:

Yes, improving or obligation for disclosing social information help to confirm the impact of this information on the commitment of the employee because the increased attention to human resources, products and contributions to community service as well as disclosing CSRD could obtain most benefits to employees, whether the benefits are tangible such as bonuses, training etc. or intangible such as gaining motivation, pride and increasing loyalty with the employee of the bank.

Most of the eight interviewees mentioned that most companies in Libya Most of Libyan companies are committed to showing the most information about the employees and consumers and this information increase from year to year which this may lead to improving employee commitment.

I think that there is an indirect effect due to the commitment to social disclosure through the improvement of the amount of social information from year to year in the annual report and especially the human resources information on employee commitment.

They also think that non-disclosure of CSR activities would give a bad reason to their employees for decreasing employee commitment as mentioned in the following quotation. Eleven (39\%) think that the impact of CSRD on employee commitment may relay on establishing sustained commitment to improve CSRD.

Yes, to some extent, because the lack of commitment for disclosing social information would be given the justification or reason to the employee that there is a problem in the company, it therefore leads to reduce the commitment of the employee.

On the other hand, six managers (21\%) believe that establishing a sustained commitment in a company to improve CSRD did not find the impact of CSRD on employee commitment. They think that employee commitment was not the main objective to improve CSRD; therefore companies increase a level of CSRD for improving their financial performance and gaining a good reputation or maintaining their reputation. In addition, the remaining three (11\%) did not know whether this commitment led to the effect of CSRD on employee commitment.

Perhaps the company is seeking to achieve other goals in order to obtain a greater share or increase sales, maximize profits or to obtain a good reputation, but it is not intended to increase or improve the employee's commitment through increasing social disclosure in the annual report... because employees consider publishing social information, especially which related to human resources to serve their interests, so they seek to increase their skills and improve its performance in order to take advantage of these activities provided by the company.

Eventually, the findings partially support the research question. The key result is that most managers believe that CSRD in terms of employee and consumer disclosures are closely associated with employee commitment than of CSRD in terms of community and environmental disclosures. More specifically, the findings explain that higher level of employee and consumer disclosure can increase and improve employee commitment in Libyan companies. However, higher level of environmental and community disclosures do not lead to increase employee commitment in the selected sample.

\section{Discussion}

The results of this paper have emerged concerning the extent of the association between CSRD and employee commitment, although previous literature mentioned that most companies do not understand the importance of 
CSRD in their annual reports. In addition, these companies are not aware the impacts of CSRD on their business outcomes. Furthermore, there is no motivation to disclose CSR activities in their annual reports because the disclosure of CSR activities is voluntary in most developing countries such as Libya. This concern is emerged due to the pressure and claimant of stakeholders, in particular employee and management. The impact of CSR activities and CSRD also create more pressure on firms from several stakeholders to enhance their organisational performance. Companies attempt to have good relation with their stakeholders through using an appropriate communication channel to maintain their performance. This communication can also influence on their environmental and social performance and CSRD. These companies have become aware the importance of CSR information in their annual reports and the extent of the effect of these information on employee commitment. They realize that the success of a firm relies on the extent to which the firm is capable of managing its relationship with main groups, such as shareholders, debt holders, and employees. Therefore, stakeholders consider information about CSR activities in annual reports is an effective factor on employee commitment.

In the results of this study, it became clear that both level of employee and consumer disclosure have a positive relationship with employee commitment. The perceptions of the financial managers and information managers correspond with stakeholder theory that predicts a positive relationship between the two types of CSRD and employee commitment. The results in this study provided some evidences about this relationship in the following paragraphs.

This finding relates strongly to the perception of managers about level of employee information disclosure, consumer information disclosure and employee commitment. It is clear that level of both employee and consumer disclosure can affect employee commitment through the following results. This effect is working due to the following some reasons. First, employee and consumer activities and disclosure can attract and retain good employees. Both of them can also attract better job applicants and lead to increasing organisational commitment on their part if they are the aware of the importance of CSR for businesses. In addition, employee and consumer information disclosure may increase current employees' morale and motivation as well as their commitment, sticking and loyalty to the company, which in turn may lead to achieving company's goals such as financial outcomes. Furthermore, companies that disclose CSR activities in their annual reports may give confidence and obtain employees sense of belonging and pride towards a company's products. The results of this paragraph in this study are consistent with the results of Peccei et al. (2005), Lawler et al. (1995), Lawler et al. (2001) and Pfeffer (1996) indicated that disclosure is seen as an important factor in management transparency, motivation, yielding benefits in employee satisfaction and management, and therefore in business performance. the results of Peccei et al. (2005) found that there is a significant positive direct and direct relationship between the type of information disclosed, the level of employee organisational commitment and the performance outcome involved, but both direct and direct relationship depends on the differences between the levels of employee organisational commitment and the performance outcome involved. In this regard, information disclosed about wage levels is positively related to employee commitment, but unrelated to productivity. These findings are consistent with some studies indicated in the literature review section (Branco \& Rodrigues 2006).

Second, high level of employee and consumer information disclosure can improve a company's reputation which in turn, affects employee commitment level. The positive information about these activities would create good image/reputation which in turn may be reflected on employees through performing their responsibilities towards their companies. The results of Branco and Rodrigues (2009) suggested that companies which have a good CSR reputation and CSR performance relating to their employees is good, recognize the need to use CSRD also to affect their perception of its reputation. This means that having good communication channel between companies and their employees lead to improving employee commitment and company's reputation. It also means good reputation with high level of CSRD in particular employee and consumer information disclosure is likely to improve employee commitment.

Third, the credibility with a certain level of information disclosure about some items of employee and consumer activities has major effect on employee commitment. More specific, information disclosure about salaries, training, rewards, quality product and product development are considered as the most important factors which in turn reflect positively on employee's performance. In effect, both relationship and effect refer to pressure from stakeholders. Pressure from internal and external stakeholders strongly influences companies to maintain a positive employee commitment (Branco \& Rodrigues 2006). Particularly, the consumers and potential employees and actual employees' pressure consider the main reason to identify this effect, therefore investments in CSR activities have internal benefits to help a company in developing new human resources.

Finally, the results of this study revealed that the awareness of management about the importance of CSRD plays a significant role in improving both CSRD and employee commitment in a company. Top management control 
employee commitment through good communication. In this regard, Hatch and Schultz (1997, p. 359) stated that top management make "deliberate attempts to influence public impression." Companies are aware of the positive association between CSRD and a strong employee commitment through pressure from stakeholders such as employees. On the other hand, there is a negative association between poor CSRD and employee commitment through stakeholder's reactions, in particular to company's products. This paper indicates a positive association between higher levels of employee and consumer disclosure with employee commitment.

\section{Summary and Conclusion}

This paper analyses the relationship between CSRD on employee commitment by a sample of the Libyan companies in four sectors (manufacturing sector, banks and insurances sector, services sector and mining sector), using a theoretical framework which combines stakeholder theory. This framework shows that an importance of CSRD related to four categories (environmental activities, consumer activities, community activities and employee activities) to stakeholders. Managers and employees increasingly require considering CSRD as a signal of improved CSR conduct in those fields because disclosure affect the business performance such as a company reputation. CSRD also leads to important results in creation or deletion of other fundamentally intangible resources, and may help build a positive commitment image with employees and managers. By demonstrating that a company does emerge CSR activities for their enhancing organisational performance, whereas non-emerging CSR can destroy organisational performance for a company, hence stakeholders require their companies to disclose CSR activities in their annual reports.

The results in this paper indicate that companies exhibit greater concern to improve employee commitment via an increase of some types of CSRD in annual reports. In this regard, to improve employee commitment in these sectors, there is greater concern for consumer disclosure and employee disclosure. On the other hand, there is no concern for environmental disclosure and community involvement disclosure to improve employee commitment. Hence, the results of this paper provide a good support for the use of a combination of stakeholder theory with resource-based perspectives to explicate the impact of CSRD on employee commitment by Libyan companies.

This paper has a number of contributions and limitations: first, it presents the first empirical data related to Libyan companies to the previous research on CSRD; second, it extends previous research that links level of CSRD with employee commitment using a combination of institutional and resource-based perspectives. Third, it reveals the nature of the relationship between level of CSRD and employee commitment in spite of a lack of CSR data of developing countries comparing with developed countries. However, this paper focuses on only CSRD in annual reports, although these companies use other mass communication mechanisms. Therefore, the future research should use other mass communication mechanism such as internet website to explore the relationship between CSRD and employee commitment in Libyan companies.

\section{References}

----. (2004). Corporate social responsibility and marketing: an integrative framework. Journal of the Academy of Marketing Science. 32(1), 3-19. http://dx.doi.org/10.1177/0092070303258971

----. (2008). Factors influencing social responsibility disclosure by Portuguese companies. Journal of Business Ethics, 83(4), 685-701. http://dx.doi.org/10.1007/s10551-007-9658-z

----. (2009). Exploring the importance of social responsibility disclosure for human resources. Journal of Human Resource Costing \& Accounting, 13(3), 186-205. http://dx.doi.org/10.1108/14013380910995494

Aguilera, R. V., Rupp, D. E., Williams, C. A., \& Ganapathi, J. (2007). Putting the S back in corporate social responsibility: A multi-level theory of social change in organizations', Academy of Management Review, 32, 836-63. http://dx.doi.org/10.5465/AMR.2007.25275678

Ahmad, N. S. M. (2005). Corporate Environmental Disclosure in Libya: Evidence and Environmental Determinism Theory, Napier University

Albinger, H. S., \& Freeman, S. J. (2000). Corporate social performance and attractiveness as an employer to different job seeking populations. Journal of Business Ethics, 28(3), 243-53. http://dx.doi.org/10.1023/A:1006289817941

Backhaus, K. B., Stone, B. A., \& Heiner, K. (2002a). Exploring the relationship between corporate social performance and employer attractiveness. Business \& Society, 41(3), 292-310. http://dx.doi.org/10.1177/0007650302041003003

Brammer, S., \& Millington, A. (2005). Corporate reputation and philanthropy: an empirical analysis. Journal of Business Ethics, 61(1), 29-44. http://dx.doi.org/10.1007/s10551-005-7443-4 
Brammer, S., Millington, A., \& Rayton, B. (2007). The contribution of corporate social responsibility to organizational commitment. The International Journal of Human Resource Management, 18(10), 1701-19. http://dx.doi.org/10.1080/09585190701570866

Branco, M. C., \& Rodrigues, L. L. (2006). Corporate social responsibility and resource-based perspectives. Journal of Business Ethics, 69(2), 111-32. http://dx.doi.org/10.1007/s10551-006-9071-z

Carroll, A. B. (1979). A three-dimensional conceptual model of corporate performance. The Academy of Management Review, 4(4), 497-505. http://dx.doi.org/10.2307/257850

Cohen-Charash, Y., \& Spector, P. E. (2001). The role of justice in organizations: A meta-analysis. Organizational behavior and human decision processes, 86(2), 278-321. http://dx.doi.org/10.1006/obhd.2001.2958

Collier, J., Esteban, R., \& Street, T. (2007). Corporate social responsibility and employee commitment. Business Ethics: A European Review, 16(1), 19-33. http://dx.doi.org/10.1111/j.1467-8608.2006.00466.x

Gillham, B. (2000). The Research Interview. London, Continuum.

Greening, D. W., \& Turban, D. B. (2000). Corporate social performance as a competitive advantage in attracting a quality workforce. Business \& Society, 39 (3), 254-280. http://dx.doi.org/10.1177/000765030003900302

Hanafi, R. A. (2006). An exploration of corporate social and environmental disclosure in Egypt and the UK: a comparative study. University of Exeter, UK.

Hasseldine, J., Salama, A. I., \& Toms, J. S. (2005). Quantity versus quality: the impact of environmental disclosures on the reputations of UK Plcs. The British Accounting Review, 37(2), 231-48. http://dx.doi.org/10.1016/j.bar.2004.10.003

Hatch, M. J., \& Schultz, M. (1997). Relations between organizational culture, identity and image. European Journal of Marketing, 31(5/6), 356-65. http://dx.doi.org/10.1108/eb060636

Hsu, I. (2006). Enhancing employee tendencies to share knowledge-Case studies of nine companies in Taiwan. $\begin{array}{lllll}\text { International journal of information management, } & \text { 26(4), } & \text { 326-38. }\end{array}$ http://dx.doi.org/10.1016/j.ijinfomgt.2006.03.001

Kamla, R. (2007). Critically appreciating social accounting and reporting in the Arab Middle East: a postcolonial $\begin{array}{lllll}\text { perspective'. Advances in } \quad \text { International } & \text { Accounting, } & \text { 20, }\end{array}$ http://dx.doi.org/10.1016/S0897-3660(07)20005-4

Kleiner, M. M., \& Morris, M. (1988). Providing Business Information to Production Workers: Correlates of Compensation and Profitability. Industrial and Labor Relations Review, 41, 4-23

Koh, H. C., \& Boo, E. H. Y. (2001). The link between organizational ethics and job satisfaction: A study of managers in Singapore. Journal of Business Ethics, 29(4), 309-24. http://dx.doi.org/10.1023/A:1010741519818

Lawler, E. E., Mohrman, S. A., \& Benson, G. (2001). Organizing for high performance: employee involvement, $T Q M$, reengineering, and knowledge management in the Fortune 1000: the CEO report. Jossey-Bass San Francisco, CA.

Lawler, E. E., Mohrman, S. A., \& Ledford, G. E. (1995). Creating high performance organizations: Practices and results of employee involvement and total quality management in Fortune 1000 companies. Jossey-Bass San Francisco, CA.

Maignan, I., \& Ferrell, O. C. (2001). Corporate citizenship as a marketing instrument. European Journal of Marketing, 35(3/4), 457-84. http://dx.doi.org/10.1108/03090560110382110

Maignan, I., Ferrell, O. C., \& Hult, G. T. M. (1999). Corporate citizenship: Cultural antecedents and business benefits. Journal of the Academy of Marketing Science, 27(4), 455-69. http://dx.doi.org/10.1177/0092070399274005

Marshall, C., \& Rossman, G. (1999). Designing Qualitative research. Sage Publications Ltd, London.

Mathews, MR. (1993), Socially responsible accounting. Chapman \& Hall, London.

Meyer, J. P., Stanley, D. J., Herscovitch, L., \& Topolnytsky, L. (2002). Affective, continuance, and normative commitment to the organization: A meta-analysis of antecedents, correlates, and consequences. Journal of vocational behavior, 61(1), 20-52. http://dx.doi.org/10.1006/jvbe.2001.1842

Miles, M. B., \& Huberman, A. M. (1994). Qualitative data analysis: An expanded sourcebook. SAGE publications, Inc, Claifornia. 
Peccei, R., Bewley, H., Gospel, H., Willman, P., \& Street, P. E. (2005). Is it good to talk? Information disclosure and organizational performance in the UK. British Journal of Industrial Relations, 43(1), 11-39. $\mathrm{http}: / / \mathrm{dx}$. doi.org/10.1111/j.1467-8543.2005.00343.x

Peterson, D. K. (2004). The relationship between perceptions of corporate citizenship and organizational commitment. Business \& Society, 43(3), 296-319. http://dx.doi.org/10.1177/0007650304268065

Pfeffer, J. (1996). Competitive advantage through people: Unleashing the power of the work force. Harvard Business Press. London.

Post, F. R. (2003). A response to "the social responsibility of corporate management: a classical critique. American Journal of Business, 18(1), 25-35. http://dx.doi.org/10.1108/19355181200300002

Rettab, B., Brik, A. B., \& Mellahi, K. (2009). A study of management perceptions of the impact of corporate social responsibility on organisational performance in emerging economies: The case of Dubai. Journal of Business Ethics, 89(3), 371-90. http://dx.doi.org/10.1007/s10551-008-0005-9

Rupp, D. E., Ganapathi, J., Aguilera, R. V., \& Williams, C.A. (2006). Employee reactions to corporate social responsibility: An organizational justice framework. Journal of Organizational Behavior, 27(4), 537-49. http://dx.doi.org/10.1002/job.380

Toms, J. S. (2002). Firm resources, quality signals and the determinants of corporate environmental reputation: some UK evidence. The British Accounting Review, 34(3), 257-82

Turban, D.B., \& Greening, D.W. (1997). Corporate social performance and organizational attractiveness to prospective employees. The Academy of Management Journal, 40(3), 658-72. http://dx.doi.org/10.2307/257057

Turker, D. (2009). 'How corporate social responsibility influences organisational commitment. Journal of Business Ethics, 89(2), 189-204. http://dx.doi.org/10.1007/s10551-008-9993-8

van der Laan Smith, J., Adhikari, A., \& Tondkar, RH. (2005). Exploring differences in social disclosures internationally: A stakeholder perspective. Journal of Accounting and Public Policy, 24(2), 123-51. http://dx.doi.org/10.1016/j.jaccpubpol.2004.12.007

Viswesvaran, C., Deshpande, S. P., \& Joseph, J. (1998). Job satisfaction as a function of top management support for ethical behavior: A study of Indian managers. Journal of Business Ethics, 17(4), 365-71. http://dx.doi.org/10.1023/A:1017956516324

Waller, D. S., \& Lanis, R. (2009). Corporate Social Responsibility (CSR) Disclosure of Advertising Agencies: An Exploratory Analysis of Six Holding Companies' Annual Reports. Journal of Advertising, 38(1), 109-22. http://dx.doi.org/10.2753/JOA0091-3367380107

WBCSD. (1998). World business council for sustainable development: Corporate social responsibility. WBCSD publications, Geneva.

\section{Appendix 1: Profiles of interviewees}

\begin{tabular}{|c|c|c|c|c|c|}
\hline Sectors Name & $\begin{array}{l}\text { Sectors } \\
\text { Number }\end{array}$ & $\begin{array}{c}\text { Selected } \\
\text { sectors }\end{array}$ & Financial Managers & Information Managers & Total \\
\hline Manufacturing & 12 & 6 & 8 & 4 & 12 \\
\hline Services & 14 & 10 & 11 & 1 & 12 \\
\hline Banks and Insurance & 13 & 5 & 4 & 2 & 6 \\
\hline Mining & 1 & 1 & 1 & 0 & 1 \\
\hline Total & 40 & 22 & 24 & 7 & 31 \\
\hline Participants rate & & & $77 \%$ & $23 \%$ & $100 \%$ \\
\hline
\end{tabular}


Appendix 2: Summary of key findings by topics

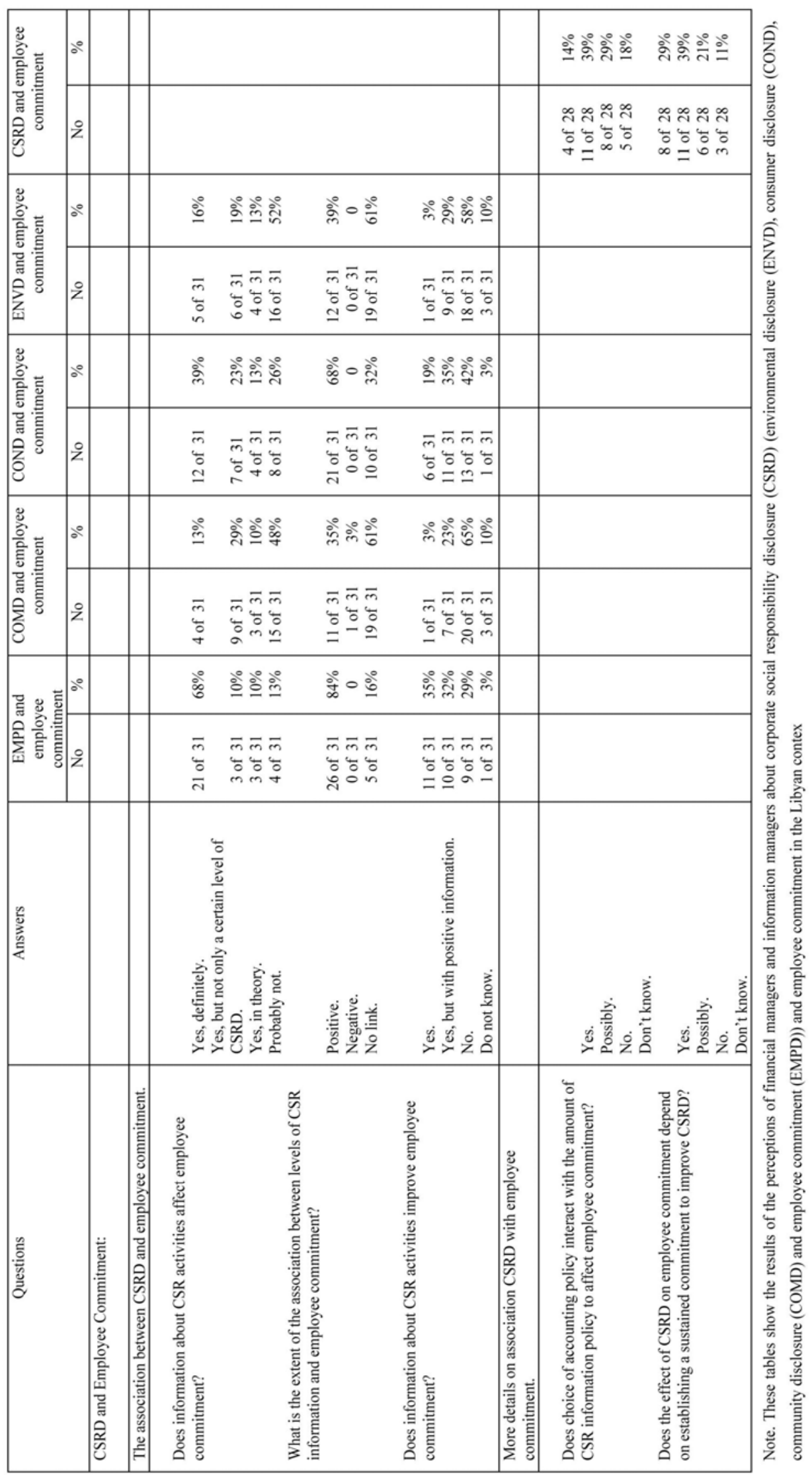

